\title{
Who Decides to Give a Gift of Fresh Flowers? The Effects of Givers and Receivers on the Likelihood of Buying Fresh Flowers for Gifts
}

\author{
Li-Chun Huang ${ }^{1}$ and Yen-Chun Lin \\ Department of Bio-Industry Communication and Development, National \\ Taiwan University, Taipei 10617, Taiwan
}

Additional index words. floral gifts, floral consumption, gift giving, gifts, multinomial logistic regression analysis

\begin{abstract}
As gifts are an important market sector for selling fresh flowers, this study investigated the effects of the characteristics associated with the dyads of givers and receivers on the probability of buying fresh flowers as gifts. Based on the theory of gift giving, several factors were hypothesized to influence the probability of buying fresh flowers as gifts, including givers' financial capability and the perceived gift values of flowers, as well as knowledge of receiver's needs, preferences, and difficulty to please. A self-administered questionnaire survey was conducted to test the hypotheses. Results of the statistical analysis based on 394 valid questionnaires revealed that the perceived gift values of flowers, i.e., the economic value, functional value, social value, and expressive value, were the most important factors for the consumer decision of whether to buy fresh flowers as gifts. However, different gift values were emphasized for fresh flowers across different relational ties. For example, economic value was the key value when the receivers were parents, whereas social value and expressive value were emphasized when the receivers were romantic partners. Different from many previous studies, this study revealed that financial capability did not influence the likelihood of givers deciding to purchase fresh flowers for gifts. The study results implied that when promoting fresh flowers for gift use, the gift values of fresh flowers need to be emphasized to consumers.
\end{abstract}

Because of their beauty and symbolic meanings of love, status, belonging, celebration, sympathy, etc., flowers have long been used as gifts to enhance social relationships, or to symbolize something important in life rituals (Ziegler, 2007). When used for gifts, flowers are perceived as emotional gifts and are used mainly to convey givers' affection to the receivers or relationships (Yue et al., 2009). Gifts of flowers stimulate more feelings of caring and warmth compared with other alternatives, and are thus beneficial for the facilitation of social relationships (SAF, 2012a). Actually, gift giving is one of the primary forces driving the growth of the global floral industry: nearly $60 \%$ of Americans have given flowers or houseplants as gifts at least once, and $67 \%$ of fresh flower purchases are for gifts (SAF, 2012b, 2012c). In Asian countries, about $80 \%$ of cut flowers are purchased for gifts or commercial purpose in Japan, and $60 \%$ of potted plants

Received for publication 2 Mar. 2014. Accepted for publication 6 June 2014 .

This research was funded by the National Science Council of Taiwan under Grant NSC 101-2410-H-002-192.

The authors would like to thank the anonymous reviewers and editors for their thoughtful comments and suggestions.

${ }^{1}$ To whom reprint requests should be addressed; e-mail lihuang@ntu.edu.tw. purchases were for gifts in Korea (Kim et al., 1999). Academic research also demonstrates that gift giving is a key factor that drives consumers in Taiwan to purchase flowers (Huang, 2005).

As gift giving is such an important driver of fresh flower purchases, researchers of floral marketing have investigated some important factors behind floral gift purchases, such as consumers' attitudes, purchase intention, purchase frequency, and the price they are willing to pay. For instance, a study by Scammon et al. (1982) has examined the socioeconomics, purchase motivation, and purchase process for consumers who buy flowers for obligatory gifts. Yue et al. (2009) found that most of the consumers perceive flowers as a pleasant and "hard-togo-wrong" gift due to the stability of the symbolism associated with flowers. Rihn et al. (2011) compared differences in consumer attitudes toward using fresh flowers as gifts between generations X (33 to 50 years old) and Y (18 to 32 years old), and found that younger consumers see floral gifts more negatively. For example, many young consumers perceive floral gifts as expensive, impractical, extravagant, or not unique enough to identify the giver. Consumer behavior for holiday floral gifts has also interested some researchers. For example, Lai and Huang (2013) studied the characteristics of romantic relationships and their effects on the probability of buying flowers as a romantic gift for Valentine's Day, the most important holiday for selling fresh flowers. Their study results revealed that passion and spiritual fulfillment encouraged consumers to buy their intimate partners flowers on Valentine's Day.

Although some important knowledge on consumer floral gift giving has been explored, the basic question of why flowers are picked out from numerous gift alternatives remains unanswered. There is still much to learn about floral gift giving, including the basic question of why consumers buy or don't buy fresh flowers for gifts, to expand the retail market for fresh flowers. This study was intended to address this deficiency. The objectives for this study were 1) to investigate the effect of givers' knowledge of the character of the receivers, in terms of preferences, needs, and difficulty to please, on the decision of whether to buy a floral gift; 2) to investigate the effect of givers' perceived gift value of flowers on the probability of buying a floral gift; and 3) to evaluate the effect of givers' financial capability on the decision to buy a floral gift.

All the study objectives were examined across different relation ties between the givers and recipients, including parents, romantic partners, and others, because in the real world different relationships are emphasized for different gift-giving holidays. For example, the mother-child relationship is emphasized on Mothers' Day, so mothers are the key persons for whom children should buy gifts to convey their respect and love. Similarly, fathers for Fathers' Day, lovers for Valentine's Day, good friends and family for Christmas or Chinese New Year, etc., are the principle recipients. Carrying out the study objectives across different relationships not only allows the authors to assess the study outcomes more thoroughly but also enhances the practicality of the study results for selling floral gifts at different holidays.

\section{Theoretical Framework}

Gift giving is a very common social behavior in daily life, and is done to enhance the social relationship between the dyad of the giver and receiver. In gift giving, givers' affection toward the receivers and their relationships is translated to the receivers with gifts (Banks, 1979; Schwartz, 1967; Sherry, 1983). From the receiver's standpoint, to accept the gift means to accept the intention of the giver. That is, a gift acts as a communication tool in which the giver encodes an intended message, and the receiver needs to decode the message from the context of the gift, in terms of value, quality, symbolism, occasion, etc., to understand the giver's thought (Larsen and Watson, 2001; Schwartz, 1967; Sherry, 1983). Even though many resources can be used as gifts, such as material goods, assistance, or other kinds of service (Belk and Coon, 1993), the givers need to carefully decide what to give to avoid being misunderstood. The appropriateness of gifts is decisive for the effectiveness of gift giving. 
Why does an appropriate gift work well for a relationship? The appropriateness of a gift indicates the depth of a giver's understanding of the recipient's needs, desires, preferences, and/or the relationship status. Actually, the receiver sees the fitness or appropriateness of the gift object as a cue for judging the giver's efforts and sincerity. Besides, the receiver also perceives the gift as an indicator of the giver's caring for the receiver and the relationship. Via the appropriateness of the gift, the receiver feels understood and cared for. It makes the receiver more willing to commit to the relationship, and thus the relationship status is more ensured and stable (Belk, 1996). From the standpoint of social psychology, an inappropriate gift makes the receiver feel misinterpreted or degraded, and see the giver as insincere and unfriendly (Schwartz, 1967). Therefore, an inappropriate gift insults the receiver, and thus is very harmful to a relationship. Since gifts also reflect a giver's self-identification, an inappropriate gift also degrades the giver's self (Schwartz, 1967). A failed gift giving will have negative impact on the relationship, in particular to relationships with loose ties. For instance, failed gift giving will have more impact on relationships with friends, colleagues, and in-laws than on close relationships with family members, such as children, parents, and spouses (Roster, 2006).

Due to the impact of the appropriateness of a gift for a social relationship, searching for a gift can be an anxious task for the giver. To make the right gift selection, the giver needs to refer to different information to decide what to give. Previous studies had different findings regarding the cues that a giver relies on to decide what to give (Belk, 1982; Caplow, 1984; Sherry et al., 1993; Wooten, 2000), including 1) receiver's preferences, taste, needs, and how difficult they are to please (Goodwin et al., 1990; Otnes et al., 1993; Schiffman and Cohn, 2009; Sherry, 1983); 2) the intimacy of the relationship (Caplow, 1982; Cheal, 1987; Joy, 2001; Larsen and Watson, 2001; Sherry, 1983; Wagner et al., 1990); and 3) the giver's self-identification and affluence (Cheal, 1986; Larsen and Watson, 2001; Neisser, 1973; Schwartz, 1967; Sherry, 1983).

The information most often referred to for selecting an appropriate gift is the characteristics of the receiver (Goodwin et al., 1990). No matter whether the giver's motivation for gift giving is altruism, obligation, or manipulation, most of the goals of gift giving need to be achieved via pleasing the receiver. Thus, it is reasonable for the givers to refer to the characteristics of the receivers to decide what to give. Actually, finding a gift that fits the needs and preferences of the receiver is an essential rule in the process of gift exchange (Schiffman and Cohn, 2009). However, some receivers are difficult to find appropriate gifts for. Many reasons may make it hard to please the receivers, like their fastidious personality, their affluence, their naturally low demand for material goods or services, or the giver not being close enough to the receiver to know the receiver's preferences or needs (Otnes et al., 1993). Based on these aforementioned findings, we drew the first hypothesis for our study:

H1: Givers' knowledge of receivers' preferences, needs and fastidious personality influences their decision of whether to buy fresh flowers as gifts.

Due to the impact of the appropriateness of a gift for a relationship, generally the giver will pick one that is able to fulfill the function of gift giving. Gifts have four kinds of value for relationships, the economic value, functional value, social value, and expressive value, which refer, respectively, to their economic worth, utilitarian characteristics, ability to construct social ties or maintain relationships, and being expressive of the giver's self-identity (Larsen and Watson, 2001). The economic value of a gift is determined by its scarcity, monetary price, and alternative sources of supply, and the functional value of a gift is determined by its capacity for functional, utilitarian, or physical performance, whereas the social value is its ability to help establish social ties or affect their degree of intimacy. The expressive value of a gift is determined by its capacity to convey a giver's self-identity. These four values are not only a means for the giver to convey messages and self-identity but also serve as important cues for the receiver to interpret the giver's personality, taste, thoughts, and affections toward the receiver and their relationship. We thus anticipated that the perceived gift value of flowers would influence consumers' decision of whether to buy floral gifts:

H2: Givers' perception of the gift value of fresh flowers influences their decision of whether to buy fresh flowers as gifts.

The type of relationship influences the intimacy of the relationship, the social role of the giver vis-à-vis the receiver, as well as the social norm and taboo of gift exchange (Belk, 2005; Burgoyne and Routh, 1991; Joy, 2001; Sherry, 1983). Thus, it is very likely for the social ties to influence the giver's gift selection. Larsen and Watson (2001) divided the social ties in gift giving into romantic partners, parent-child, grandparent-grandchild, siblings, friends, and kin. Gift giving was emphasized more for spousal relationships than for parent-child relations, close relatives, close friends, or distant relatives (Mortelmans and Sinardet, 2004). According to a consumer survey regarding the average person's spending on Christmas gift shopping for the United States in 2011, on average, a person spent $\$ 403.26$ on gifts for family, $\$ 68.23$ on those for friends, $\$ 21.06$ on gifts for coworkers, and $\$ 23.39$ on those for others (including pets, babysitters, etc.) (National Retail Federation, 2011). Generally speaking, highly valued and expressive gifts will go to the receiver who is in an intimate relationship with the giver. For instance, attributes related to symbolic meanings and quality, rather than price, are more focused on when making a gift purchase for a best friend, whereas utilitarian attributes are emphasized for a new neighbor (Wagner et al., 1990); gifts for family or close friends are usually more expressive, expensive, and matching the needs of the receivers, compared with those for the receivers in a general hi-bye relationship (Joy, 2001). This may be related to the difference of the motivation for gift giving. In an intimate relationship, gifts are usually presented voluntarily and more often from the motivation of pure love, and thus receivers' benefits, instead of cost benefit or reciprocity, are of greater concern for the gift giving in an intimate relationship (Goodwin et al., 1990; Joy, 2001). We thus hypothesized:

H3: What cues are referred to by givers to decide whether to purchase fresh flowers as gifts depends on the type of relationship with the receivers.

Even though givers may refer to various kinds of information to decide on the gift, their final decision may be limited by their financial capacity. If they find a gift very appropriate but at an unaffordable price, the givers may switch to other alternatives. The more distant the relationship, the more significant price will be in influencing individuals' gift purchase decision (Wagner et al., 1990). We anticipated a similar behavior pattern would be found in our study, and thus hypothesized:

H4: Givers' financial capacity influences their purchase decision of whether to buy fresh flowers as gifts.

\section{Materials and Methods}

Sampling. In Taiwan, gift giving is a social behavior more prevalent among the individuals who have higher socioeconomic status (Kuo, 1997). The census indicated that in Taiwan, the urban population has higher education and income compared with the rural population (National Statistics of Taiwan, 2011). Therefore, the authors recruited the sample from Taipei, Taichung, and Kaohsiung, which are the main cities located in the north, center, and south of Taiwan, to test the research hypotheses. Each of these three cities is made up of several administrative districts: 12 administrative districts for Taipei, 8 for Taichung, and 11 for Kaohsiung. In this study, three administrative districts were randomly selected from each city using Excel software (Microsoft, 2003) to serve as a sampling pool: Da-An, Shih-Lin, and Nei-Hu were the three districts selected for Taipei; Si-tun, North District, and West District were chosen for Taichung; whereas Cian-jhen, Gu-Shan, and Yan-Cheng were the three selected for Kaohsiung.

The survey was conducted from 2 May to 30 May, 2011, and only consumers who were 18 years old or older and had real experience in gift giving in the past year were invited to 
participate in this study. Potential participants were first screened with the question "Have you given gifts to someone in the past year?" If the answer was yes, they were invited to participate in the survey. The limitation of having a gift giving experience within 1 year was set to ensure that the participants had vivid memory of their gift giving experience, to provide the researchers with unbiased data. According to one research report, clothing, personal items, art, jewelry, food, wines, appliances, home furnishing accessories, flowers, etc., are the most common items purchased for gifts (Banks, 1979; E-ICP, 2006). Therefore, to recruit different types of gift givers to participate in this study, we accessed the potential participants not only from florists, but also from the retail channels selling various gift items but not flowers, including gift specialty stores, department stores, souvenir shops, museums, etc.

Participants were first informed with a consent letter carrying the message of study objectives and guarantees about the anonymity and usage of their personal data. Most of the participants took $\approx 10-15 \mathrm{~min}$ to complete the self-administered questionnaire. After completion, every participant received a shopping bag priced at NT\$ (New Taiwanese dollars) 30 ( $\approx$ US $\$ 1.04)$ as compensation for their participation. A total of 400 consumers were recruited: 200 participants were sampled from Taipei, 80 from Taichung, and 120 from Tainan, based on the population ratio of these three cities (Accounting and Statistics Office of the Executive Yuan of Taiwan, 2011). Six questionnaires were invalid because more than three questions were missed or they were completed by consumers who were under 18 years old. As a result, 394 questionnaires were used for the statistical analysis.

Questionnaire design. Self-administered questionnaires were used as the instrument of data collection. There was a statement used to direct the participants to recall their most impressive experience in gift giving in last year, then to answer the questionnaire items based on that recalled experience. All the measurement items were developed based on the findings of previous studies to ensure the validity of the questionnaire (Table 1). To ensure the comprehensibility of the questionnaire, the draft version of the questionnaire was pretested through a pilot study in Apr. 2011 with 10 subjects, who were 18 years old or older, the same age range as the targeted sample of this study.

With the questionnaire, the participants were first asked to indicate their relationship with the receivers. The second section was to measure participants' familiarity with the receivers' preferences, needs, and difficulty to please. Participants' responses were measured with multiple items on a 5-point Likert scale $(1=$ strongly disagree, $2=$ disagree, $3=$ neutral, $4=$ agree, $5=$ strongly agree). The next section was used to measure participants' perception toward the gift value of flowers, e.g., the economic value, functional value, social value, and expressive value of floral gifts. All the responses were measured with multiple items on a 5-point Likert scale.

The third section of the questionnaire was developed to measure participants' real gift choice with a 3-level categorical scale: "fresh flowers," "fresh flowers plus nonfloral gifts," and "nonfloral gifts." The last section of the questionnaire was designed to record the demographics of the participants, in terms of gender, age, education level, occupation, and personal monthly income, all measured with categorical scales except age. The participants were asked to indicate their ages in numbers.

Statistical analysis. Scale reliability was accessed with Cronbach's $\alpha$ to ensure the internal consistency of the measurement items, as presented in Table 1. The statistical results showed that the reliability of all the scales was at a satisfactory level, being a Cronbach's $\alpha$ higher than 0.70 , the minimum acceptable level for scale reliability (Hair et al., 2010).

Multinomial logistic regression analysis was applied to investigate the effects of the independent variables on the likelihood of buying fresh flowers as gifts. All statistical analyses were processed with the statistical software of SPSS 16.0 (SPSS, 2007).

In the regression model, the variable of "receivers' preferences" denoted the degree of giver's familiarity with receiver's preferences, named RE_PREF, whereas the variable "receiver's needs" referred to the degree of giver's awareness of receiver's needs, named RE_NEED. The independent variable "difficulty to please" indicated the giver's evaluation regarding the degree of the difficulty to please the receiver, termed RE_DIFF in the regression model. These three variables were intended to evaluate the effects of receivers' traits on givers' decision about buying fresh flowers for gifts.

The gift value of flowers was measured from four dimensions, including the economic value, functional value, social value,

Table 1. Questionnaire used to measure the variables of givers' relationships with receivers, knowledge of receivers' preferences, needs, and difficulty to please, perceived gift value of flowers, and gift choice for the survey conducted in this study.

\begin{tabular}{|c|c|c|c|}
\hline Variables & Items & Theoretical base & Cronbach's $\alpha$ \\
\hline Receivers' preferences & $\begin{array}{l}\text { 1. I am familiar with his/her hobbies. } \\
\text { 2. I know his/her tastes. } \\
\text { 3. I know what he/she is interested in. }\end{array}$ & $\begin{array}{l}\text { Caplow (1984); Schiffman } \\
\text { and Cohn (2009); } \\
\text { Sherry (1983) }\end{array}$ & 0.854 \\
\hline Receivers' needs & $\begin{array}{l}\text { 1. I know what he/she wants. } \\
\text { 2. I know what he/she lacks. }\end{array}$ & $\begin{array}{l}\text { Schiffman and Cohn (2009); } \\
\text { Wooten (2000) }\end{array}$ & 0.787 \\
\hline Difficulty to please & $\begin{array}{l}\text { 1. He/she is very picky about things. } \\
\text { 2. There are few things able to please him/her. } \\
\text { 3. He/she has everything, so it is hard to find a thing to } \\
\text { please him/her. } \\
\text { 4. He/she does not ask much for many things. } \\
\text { 5. There are few things able to make him/her happy. } \\
\text { 6. He/she will accept happily whatever I give. }\end{array}$ & $\begin{array}{l}\text { Otnes et al. (1993); } \\
\quad \text { Wooten (2000) }\end{array}$ & 0.790 \\
\hline The economic value of floral gifts & $\begin{array}{l}\text { 1. Flowers are valuable gifts. } \\
\text { 2. Flowers are precious gifts. } \\
\text { 3. Flowers are rare gifts. }\end{array}$ & $\begin{array}{l}\text { Larsen and Watson (2001); } \\
\text { Yeh and Huang (2009) }\end{array}$ & 0.791 \\
\hline The social value of floral gifts & $\begin{array}{l}\text { 1. A gift of flowers helps create a new relationship. } \\
\text { 2. A gift of flowers helps improve a relationship. } \\
\text { 3. A gift of flowers helps maintain a relationship. }\end{array}$ & $\begin{array}{l}\text { Larsen and Watson (2001); } \\
\text { Yeh and Huang (2009) }\end{array}$ & 0.915 \\
\hline The expressive value of floral gifts & $\begin{array}{l}\text { 1. A gift of flowers helps the receiver recognize the personal } \\
\text { characteristics of the giver. } \\
\text { 2. A gift of flowers allows the receiver to perceive the tastes } \\
\text { of the giver. } \\
\text { 3. A gift of flowers helps create the image of the giver. }\end{array}$ & $\begin{array}{l}\text { Larsen and Watson (2001); } \\
\text { Yeh and Huang (2009) }\end{array}$ & 0.926 \\
\hline Gifts selected & $\square$ fresh flowers; $\square$ fresh flowers plus nonfloral gifts; $\square$ nonfloral gifts & Kras (1999) & - \\
\hline
\end{tabular}


and expressive value, being marked as VA_ECON, VA_FUNC, VA_SOCI, and VA_EXPR relatively in the regression model. These four variables were aimed to measure the effects of giver's perception toward the gift value of flowers on the likelihood of buying fresh flowers as gifts.

The giver's purchasing power, i.e., financial capacity, was measured with giver's personal monthly income on a categorical scale with three levels: NT $\$ 29,999$ (US\$1042.36) or less, from NT\$30,000 (US\$1042.39) to NT\$49,999 (US\$1737.28), and NT\$50,000 (US\$1737.32) or more, labeled as IC_ONE, IC_TWO, and IC_THREE, respectively in the statistical analysis. This variable was processed as a dummy variable in the multinomial logistic regression model (Hair et al., 2010). If the individual's personal monthly income was NT\$29,999 or less, IC_ONE equaled 1, and it was 0 otherwise; IC_TWO equaled 1 if the monthly income level was from NT\$30,000 to NT\$49,999, and was 0 otherwise.

Multinomial logistic regression analysis is a regression technique used for modeling categorical dependent variables that have more than two outcome categories (Kleinbaum et al., 2008). The statistical logic of multinomial logistic regression analysis is that the logits of the odds ratios between two outcome categories of a dependent variable are in a linear function to the independent variables (Hair et al., 2010; Kleinbaum et al., 2008). A multinomial regression model predicts the probability of an outcome category by odds ratios, which compare the probability of the outcome category $j[(P(y=j)]$ with the probability of the other alternative $i[(P(y=i)]$ (Hair et al., 2010). The odds ratio can be expressed as Eq. [1].

$\frac{P(y=j)}{P(y=i)}=e^{\left(\beta_{j 0}+\beta_{j 1} \chi_{1}+\beta_{j 2} \chi_{2}+\beta_{j 3} \chi_{3}+\ldots \ldots \ldots .+\beta_{j p} \chi_{p}\right)}$

Eq. [1]

Assume there are $p$ number of independent variables $\left(\chi_{p} \mathrm{~s}\right)$, then the logit of probability of the outcome category $j[(P(y=j)]$ vs. that of the outcome category $i[P(y=i)]$ is in a linear function to the independent variables $\chi_{p}$ s. The logit form of the multinomial regression model can be expressed as Eq. [2].

$$
\begin{aligned}
\mathrm{g}_{\mathrm{j}}(x)= & \ln \left[\frac{P(y=j)}{P(y=i)}\right]=\beta_{j 0}+\beta_{j 1} \chi_{1}+\beta_{j 2} \chi_{2} \\
& +\beta_{j 3} \chi_{3}+\ldots \ldots \ldots+\beta_{j p} \chi_{p}
\end{aligned}
$$

$P(y=i)$ : the probability of the dependent outcome in category $i$

$P(y=j)$ : the probability of the dependent outcome in category $j$

$\beta_{j S}$ : the parameters for interpreting the logit of the ratio of the probability of outcome category $j[P(y=j)]$ vs. that of the baseline category $i[P(y=i)]$

How many logit regression equations will occur in the whole multinomial logistic regression model is determined by the number of the outcome categories in the dependent variable. There will be $(n-1)$ logit regression equations in the multinomial regression model when there are $\mathrm{n}$ possible outcome categories for the dependent variable (Hair et al., 2010). For the objectives of this study, there would be two multinomial logistic regression equations, because there were three outcome categories for the dependent variables, i.e., the purchase outcomes of fresh flowers, fresh flowers plus nonfloral gifts, and nonfloral gifts only. These two logistic regression equations can be expressed as Eq. [3] and Eq. [4]:

$$
\begin{aligned}
& \ln \left[\frac{P(\text { fresh flowers })}{P(\text { nonfloral gifts })}\right]=\beta_{10}+\beta_{11}(\text { RE_PREF }) \\
& \quad+\beta_{12}(\text { RE_NEED })+\beta_{13}(\text { RE_DIFF }) \\
& \quad+\beta_{14}(\text { VA_ECON })+\beta_{15}(\text { VA_FUNC }) \\
& +\beta_{16}(\text { VA_SOCI })+\beta_{17}(\text { VA_EXPR }) \\
& + \\
& +\beta_{18}(\text { IC_ONE })+\beta_{19}(\text { IC_TWO })
\end{aligned}
$$

$$
\begin{aligned}
& \ln \left[\frac{P(\text { fresh flowers plus nonfloral gifts })}{P(\text { nonfloral gifts })}\right] \\
& \quad=\beta_{20}+\beta_{21}(\text { RE_PREF })+\beta_{22}(\text { RE_NEED }) \\
& \quad+\beta_{23}(\text { RE_DIFF })+\beta_{24}(\text { VA_ECON }) \\
& +\beta_{25}(\text { VA_FUNC })+\beta_{26}(\text { VA_SOCI }) \\
& +\beta_{27}(\text { VA_EXPR })+\beta_{28}(\text { IC_ONE }) \\
& +\beta_{29}(\text { IC_TWO })
\end{aligned}
$$

$\ln \left[\frac{P(\text { fresh flowers })}{P(\text { nonfloral gifts })}\right]:$ the logit functions of the odds ratios between the outcome of "fresh flowers" vs. that of "nonfloral gifts" $\ln \left[\frac{P(\text { fresh flowers plus nonfloral gifts })}{P(\text { nonfloral gifts })}\right]:$ the logit functions of the odds ratios between the outcome of "fresh flowers plus nonfloral gifts" vs. that of "nonfloral gifts"

$P$ (fresh flowers): the conditional probability of the dependent outcome in the outcome category of buying fresh flowers for gifts

$P$ (fresh flowers plus nonfloral products): the conditional probability of the dependent outcome in the outcome category of buying fresh flowers plus nonfloral items for gifts

$P$ (nonfloral gifts): the conditional probability of the dependent outcome in the outcome category of buying nonfloral items for gifts

$\beta_{1 S}$ : the parameters for interpreting the ratio of the probability of outcome category "fresh flowers" $[P$ (fresh flowers $)]$ vs. that of the baseline category "nonfloral gifts" $[P($ nonfloral gifts $)]$

$\beta_{2 S}$ : the parameters for interpreting the ratio of the probability of outcome category "fresh flowers plus nonfloral gifts" $[P$ (fresh

\begin{tabular}{|c|c|c|c|}
\hline Demographics & Category & $\begin{array}{c}\text { Number of } \\
\text { subjects }\end{array}$ & Percentage $(\%)$ \\
\hline \multirow[t]{2}{*}{ Gender } & Male & 179 & 45.4 \\
\hline & Female & 215 & 54.6 \\
\hline \multirow[t]{6}{*}{ Age (years) } & $18-20$ & 17 & 4.3 \\
\hline & $21-30$ & 157 & 39.9 \\
\hline & $31-40$ & 94 & 23.8 \\
\hline & $41-50$ & 66 & 16.8 \\
\hline & $51-60$ & 49 & 12.4 \\
\hline & 61 or over & 11 & 2.8 \\
\hline \multirow[t]{5}{*}{ Education } & Primary school or under & 4 & 1.0 \\
\hline & Junior high & 7 & 1.8 \\
\hline & Senior high & 47 & 11.9 \\
\hline & College/university & 257 & 65.2 \\
\hline & Graduate school & 79 & 20.1 \\
\hline \multirow[t]{9}{*}{ Occupation } & Agriculture/forestry/fishing/animal husbandry & 5 & 1.3 \\
\hline & Mining/manufacturing & 54 & 13.7 \\
\hline & Commercials/service business & 186 & 47.2 \\
\hline & Government officials/military service/teaching & 36 & 9.1 \\
\hline & Students & 57 & 14.5 \\
\hline & Homemaker & 35 & 8.9 \\
\hline & Retired & 5 & 1.3 \\
\hline & Unemployed & 3 & 0.8 \\
\hline & Others & 13 & 3.3 \\
\hline \multirow[t]{3}{*}{ Monthly income } & NT $\$ 29,999$ or less $\left(U S \$ 1042.36\right.$ or less) ${ }^{z}$ & 142 & 36.0 \\
\hline & NT\$30,000-49,999 (US\$1042.39-1737.28) & 144 & 36.5 \\
\hline & NT $\$ 50,000$ or more (US\$1737.32 or more) & 108 & 27.4 \\
\hline
\end{tabular}
flowers plus nonfloral gifts)] vs. that of the baseline category "nonfloral gifts" [P(nonfloral gifts) $]$

\section{Results}

Sample distribution. Table 2 displays the demographic distribution of the sample. A total of $54.6 \%$ of the participants were female, and $45.4 \%$ were male. Most of the participants were aged 21 to 50 years $(80.5 \%)$, were college educated $(65.2 \%)$, and

Table 2. The distribution of participants' demographics based on 394 valid questionnaires surveyed from Taipei, Taichung, and Kaohsiung, 2-30 May 2011.

${ }^{\mathrm{z} U S} \$ 1.00=\mathrm{NT} \$ 28.78$ 
had an occupation in commercial business or service industry (47.2\%). Regarding income, $72.5 \%$ of the participants reported monthly income under NT\$50,000. Compared with census data, the sample skews slightly toward females and higher socioeconomic status (Accounting and Statistics Office of the Executive Yuan of Taiwan, 2011, 2014). However, the sample is valid for testing the hypotheses for this study since females and individuals of higher socioeconomic status are involved more deeply in the social behavior of gift giving (Fischer and Arnold, 1990; Garner and Wagner, 1991; Kuo, 1997; Laroche et al., 2000).

The statistical results of multinomial logistic regression analysis. Multinomial logistic regression was run to evaluate whether the independent variables affected the gift selection differently across different relationships. Among the 394 participants with valid questionnaires, 138 had given gifts to their parents, 109 gave to their romantic partners, and 147 gave to others, such as bosses, colleagues, or friends. The overall fit of these multinomial logistic regression models was assessed with the log likelihood value, and the probability of the outcome category of "nonfloral gifts" served as the baseline for computation (Hair et al., 2010).

Among the independent variables investigated, only the perceived gift value of flowers revealed significant effects on the probability of whether to buy fresh flowers for gifts. The research hypotheses of $\mathrm{H} 1$ and H4 were rejected, i.e., givers' knowledge of receivers' fastidious personality, preferences, and needs, as well as givers' financial capacity, were insignificant for givers' decision of whether to purchase fresh flowers for gifts.
These findings held constant across the different types of relationship (Table 3). Flowers are generally perceived as emotional gifts for conveying love, caring, or other symbolic meanings, such as sympathy or apology (Haviland-Jones et al., 2005; SAF, 2012c; Ziegler, 2007). Consequently, consumers might ponder their purchase decision for floral gifts from the aspects of their emotional needs, instead of the utilitarian perspectives of receiver's preferences, needs, or difficulty to please. Meanwhile, the reason for most consumers to select gifts based on receivers' preferences, needs, or personality is to avoid the risk of wrong gifts, to avoid damage to a relationship (Goodwin et al., 1990; Otnes et al., 1993; Schiffman and Cohn, 2009; Schwartz, 1967; Sherry, 1983). As flowers are perceived as a gift of "hard to go wrong" and liked by most people (Yue et al., 2009), receivers' fastidious personality, preferences, or needs might be less likely to become the main considerations for consumers' decision of whether to buy flowers for gifts.

In the empirical market, flowers have a broad price range. They can be as expensive as luxury chocolates or fine clothing, such as large flower bouquets with luxurious packaging; or they can be sold at a very friendly price, such as for a single stem. Consumers, no matter whether upper class, middle class, or Blue Collar, can find flowers at the right price for themselves from different retail channels (American Floral Endowment, 1994). When consumers complain that flowers are "too expensive," they do not really mean that the price of flowers is unaffordable to them. Mostly they refer to the low monetary value of flowers due to short longevity, or the low utility function of flowers (SAF, 2005). Therefore, as the price of flowers is highly diverse and affordable for most consumers, the study result that income is insignificant for the consumer decision of whether to buy flowers for gifts is reasonable.

Although the research hypotheses of $\mathrm{H} 1$ and $\mathrm{H} 4$ were rejected, the statistical results proved the research hypothesis $\mathrm{H} 2$, that consumer perception of the gift value of flowers influenced the likelihood of buying fresh flowers as gifts. However, a substantial variation across different relationships was found by the stratified multinomial logistic regression analysis, as presented in Table 3. That is, which floral gift value was more prominent depended on the type of the relationship involved, in regard of the effects of the perceived gift value of flowers on the probability of purchasing fresh flowers for gifts. When the receivers were parents, the perceived economic value was the only salient variable raising the probability of the givers buying fresh flowers (odds ratio = 2.415), and the floral gifts tended to be paired with other, nonfloral gifts. There were more dimensions in the gift value of flowers influencing the likelihood of buying fresh flowers as gifts when the receivers were in a romantic relationship with the givers, including the perceived functional value, social value, and expressive value. The social value and expressive value revealed positive effects on the probability of buying a gift of fresh flowers. The perceived expressive value of floral gifts encouraged the givers to buy fresh flowers as gifts, either to pair with other gift items or not (odds ratio $=2.289,2.267$ ), whereas the perceived social value of floral gifts had the strongest positive effect on

Table 3. Summary of multinomial logistic regression analysis to evaluate the effects of givers' knowledge of receivers' preferences, needs, and difficulty to please, as well as perceived gift value of fresh flowers, on the likelihood of buying fresh flowers as gifts across different relationships with 394 valid questionnaires surveyed in Taiwan, 2-30 May 2011.

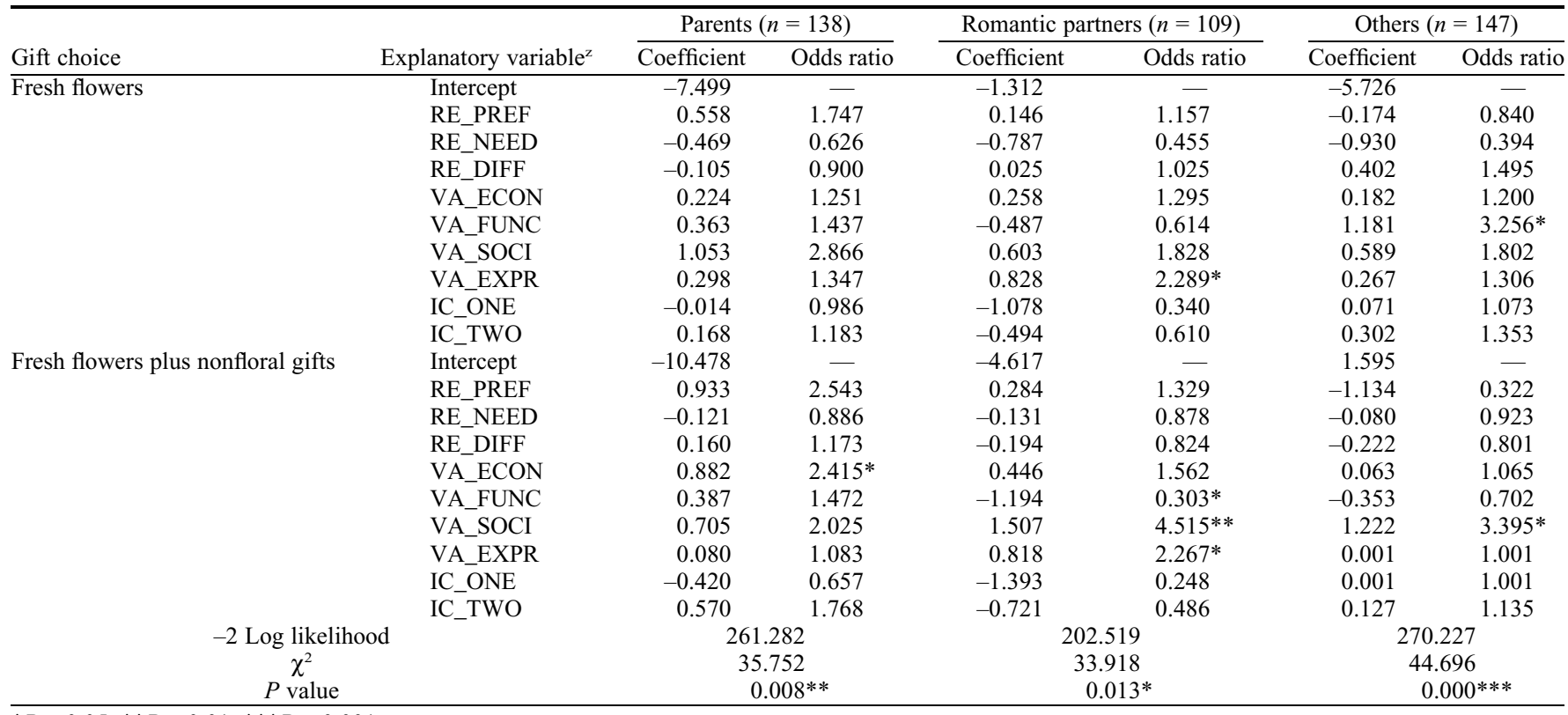


driving the givers to buy fresh flowers to pair with other goods as gifts for their romantic partners (odds ratio $=4.515$ ). In contrast, the perceived functional value of floral gifts revealed a negative effect on the likelihood of buying fresh flowers to pair with nonfloral goods for gifts (odds ratio $=0.303$ ).

The statistical results also showed that when the receivers were not part of a parentchild or romantic relationship, such as friends, colleagues, or siblings, givers' perceived social and functional values of floral gifts influenced the likelihood of buying fresh flowers as gifts. The stronger the perception of the functional value of floral gifts, the more likely the givers were to buy a gift of fresh flowers (odds ratio $=3.256$ ). The likelihood of buying fresh flowers for gifts also rose when the perceived social value was stronger (odds ratio $=3.395$ ), but in pair with other, nonfloral goods (Table 3 ).

The substantial variation caused by the difference in relational ties, as described above, may be explained by considering the motivations of gift giving in different relationships. Different relationships fulfill for individuals different social functions, and individuals are expected to play certain social roles and have certain obligations to the other person in the relationship (Otnes et al., 1993). From the aspect of sociology, families are the social unit of community that highly relies on sharing, reciprocity and mutual dependence to survive. From the perspectives of community support, gift giving is an action beyond self-interest for the family members to show their caring and share resources for mutual support (Adloff, 2006; Belk, 2005). This may urge givers to highlight the material value of a gift when selecting gifts for parents. Therefore, when givers have stronger belief in the economic value of flowers, they are likely to buy flowers for their parents, and their floral gifts for parents are more likely to be paired with other gift items.

Romantic partners, like spouses or lovers, are seen as family or quasi family. However, in addition to familial love, there is also romantic love in a romantic relationship. Romantic relationships are not something people are born into like a parent-child relationship. They tend to be fragile but important, compared with other social relationships (Komter and Vollebergh, 1997). The success of a romantic relationship is determined by factors in different dimensions, such as personal charms, mutual caring, expression of affection, and good communication (Anderson and Emmers-Sommer, 2006; Clark et al., 1999). As gift giving is a common strategy used to initiate and retain a romantic relationship (Otnes et al., 1994; Saad and Gill, 2003), individuals may anticipate that the gifts they select for their romantic partners will function in multiple dimensions, such as to express affection and love, as well as to show the charm, taste, or wealth of the giver (Belk and Coon, 1993; Rugimbana et al., 2003). By considering the efforts required for staying in a romantic relationship, the finding that the perceived social and expressive value of floral gifts increases the likelihood of buying fresh flowers as a romantic gift becomes understandable. When consumers more strongly identify these two values of floral gifts, it implies that they have a stronger belief that flowers are an ideal gift for constructing relationships and conveying self-image, all essential for the success of a romantic relationship.

In contrast, consumer belief in the functional value of floral gifts decreased the likelihood of buying fresh flowers as romantic gifts. The functional value of floral products was measured in terms of sensory enjoyment, home decoration, mood conditioning, and atmosphere generation. This value dimension denotes the material utility of fresh flowers, thus it may disassociate flowers from the notion of extravagance, and make consumers perceive of flowers as ordinary commodities. Once a romantic gift is as ordinary as commodities, its suitability for signifying the sacrifice, social power, or affections of the givers will decrease (Belk, 1996). This may diminish the power of a romantic gift. Therefore, for maximizing the efficiency of a romantic gift, consumers tend to avoid common commodities when selecting gifts for romantic partners. This helps to explain the finding that stronger belief in the functional value of floral gifts decreased the likelihood of buying fresh flowers for romantic partners.

Although the functional value decreased the likelihood of buying fresh flowers for romantic partners, it increased the probability of buying flowers as gifts when the receivers were outside the relationship of parents or romantic partners, such as bosses, colleagues, casual acquaintances, etc. (Table 3 ). When the receivers were distant in affection from the gift givers, gifts were presented mainly based on obligation or for the upkeep of a social network. In such circumstances, givers tend to give inexpensive instrumental or traditional gifts (Caplow, 1984; Joy, 2001; Wagner et al., 1990). For example, social networks in the workplace are more typically characterized as obligatory, hierarchical, or by authority ranking, rather than by family love or community support (Belk, 2005; Rupp, 2003; Ruth, 2004), so workplace relationships involve fewer emotional bonds. Thus, gift giving in the workplace is mainly for the social purpose of maintaining courtesy, social networks, or self-interest, instead of expressing family love, romantic love, or community support (Ruth, 2004). Furthermore, as the receivers are emotionally distant from the givers, it is hard for the givers to speculate about receivers' needs or preferences (Otnes et al., 1993). In such circumstances, traditional gifts tend to be the best choice for the givers, to avoid any negative consequence of giving a wrong gift (Camerer, 1988). This explains the finding that stronger perception of the functional value and social value of floral gifts enhances the likelihood of buying flowers as gifts when the receivers are outside the intimate circle of intimacy.

\section{Conclusion}

The theory of gift giving led us to assume certain factors associated with the giver and receiver would affect the likelihood of purchasing flowers as gifts. Factors assumed include givers' knowledge of receivers' preferences, needs, and difficulty to please, as well as givers' perceived value of floral gifts and financial capability. We also hypothesized that the effects of these factors would vary across different relational ties. In sum, two questions were examined in this study: 1) whether consumer knowledge of receivers' preferences, needs, and difficulty to please, as well as givers' perceived gift value of fresh flowers and financial capacity, affect the likelihood that givers will buy fresh flowers as gifts; 2) whether the effects of the hypothesized predictors on the likelihood of purchasing fresh flowers as gifts vary with differences in the relationship with the receiver.

The important findings in this study are 1) consumer knowledge of the receivers' needs, preference, and difficulty to please, as well as givers' financial capability, did not influence the likelihood of purchasing fresh flowers for gifts; 2) givers' perceived value of floral gifts saliently influenced the probability of buying fresh flowers for gifts; and 3) the type of perceived floral gift value that affects the likelihood of buying fresh flowers as gifts depends on the type of relationship. The economic value of floral gifts positively enhances the probability of buying fresh flowers as gifts for parents. When receivers are romantic partners, such as spouses or lovers, the social and expressive values of floral gifts enhance the likelihood of buying flowers for gifts. And when the receivers were in a social relationship outside of givers' intimate circle, such as the relationships of ordinary friends, colleagues, or other relationships, the functional and social values of floral gifts enhanced the probability of buying fresh flowers as gifts.

Previous studies have suggested that givers' economic capacity influences their gift choice (Wagner and Garner, 1993), and that in a close relationship givers are less likely to purchase flowers as gifts due to the givers knowing the preferences of the receivers better (Yue et al., 2009). However, this study illustrates a different finding, i.e., givers' income as well as givers' knowledge of receivers' preferences or needs did not influence the likelihood of buying fresh flowers as gifts, regardless of the intimacy of the relational ties. Clearly, to promote fresh flowers in the gift market, industry practitioners should endeavor to strengthen consumers' positive thoughts about the gift value of fresh flowers.

This study has taken a step in the direction of defining the factors that influence consumer decisions of whether to use fresh flowers for gifts. Taiwan is a typical market that is in the developing stage regarding the consumption of fresh flowers, so the approach recommended in this study will be valuable for promoting the consumption of floral gifts in the Chinese culture region of Asia, an important emerging market for the consumption of fresh flowers due to the rapid 
strengthening of economies and change of lifestyle (Belwal and Chala, 2008). However, gift giving is a social behavior highly regulated by the context of culture. The approach outlined in this study should be replicated on other culture frames to examine whether the factors identified in this study as influencing the likelihood of buying fresh flowers for gifts vary under different cultural contexts. Doing so will contribute to the accumulated understanding of why consumers select fresh flowers for gifts.

\section{Literature Cited}

Accounting and Statistics Office of the Executive Yuan of Taiwan. 2011. The population statistics. Executive Yuan of Taiwan, Taipei, Taiwan. 20 Mar. 2011. $<$ http://www.dgbas.gov.tw/ct.asp?xItem= $15408 \&$ CtNode $=4594>$.

Accounting and Statistics Office of the Executive Yuan of Taiwan. 2014. The population statistics by cities and counties. Executive Yuan of Taiwan, Taipei, Taiwan. 20 Apr. 2014. <http://ebas1.ebas. gov.tw/pxweb/Dialog/CityItemlist_o.asp>.

Adloff, F. 2006. Beyond interests and norms: Toward a theory of gift-giving and reciprocity in modern societies. Constellations 13(3):407-427.

American Floral Endowment. 1994. Shifting consumer purchase habits. Flora-Stats Research Report of American Floral Endowment. American Floral Endowment, Alexandria, VA.

Anderson, T.L. and T.M. Emmers-Sommer. 2006. Predictors of relationship satisfaction in online romantic relationships. Commun. Stud. 57(2): 153-172.

Banks, S.K. 1979. Gift giving: A review and an interactive paradigm. Adv. Consum. Res. 6: 319-324.

Belk, R.W. 1982. Effects of gift giving involvement on gift selection strategies. Adv. Consum. Res. 9(1):408-412.

Belk, R.W. 1996. The perfect gift, p. 59-84. In: C. Otnes and R.F. Beltramini (eds.). Gift giving: A research anthology. Bowling Green State Univ. Popular Press, Bowling Green, OH.

Belk, R.W. 2005. Exchange taboos from an interpretive perspective. J. Consum. Psychol. 15(1):16-21.

Belk, R.W. and G.S. Coon. 1993. Gift giving as agapic love: An alternative to the exchange paradigm based on dating experiences. J. Consum. Res. 20:393-417.

Belwal, R. and M. Chala. 2008. Catalysts and barriers to cut flower export: A case study of Ethiopian floriculture industry. Intl. J. Emer. Mkt. 3(2):216-235.

Burgoyne, C.B. and D.A. Routh. 1991. Constraints on the use of money as a gift at Christmas: The role of status and intimacy. J. Econ. Psychol. 12:47-69.

Camerer, C. 1988. Gifts as economic signals and social symbols. Amer. J. Sociol. 94:180-214.

Caplow, T. 1982. Christmas gifts and kin networks. Am. Sociol. Rev. 47:383-392.

Caplow, T. 1984. Rule enforcement without visible means: Christmas gift giving in Middletown. Am. J. Sociol. 89(6):1306-1323.

Cheal, D. 1986. The social dimensions of gift behavior. J. Soc. Pers. Relat. 3:423-439.

Cheal, D. 1987. Showing them you love them: Gift giving and the dialectic of intimacy. Sociol. Rev. 35(1):150-169.

Clark, C.L., P.R. Shaver, and M.F. Abrahams, 1999. Strategic behaviors in romantic relationship initiation. Pers. Soc. Psychol. Bull. 25:709-722.

E-ICP. 2006. An analysis to the tendency of giftgiving in Taiwan: Market change from 2001 to
2006 (in Chinese). 18 Mar. 2011. <http://www. isurvey.com.tw/5_member/login.aspx?BUrl= \%2f7_eol\%2f2_detail.aspx\%3fid\%3d1235>.

Fischer, E. and S.J. Arnold. 1990. More than a labor of love: Gender roles and Christmas gift shopping. J. Consum. Res. 17(3):333-345.

Garner, T.I. and J. Wagner. 1991. Economic dimensions of household gift giving. J. Consum. Res. 18(3):368-379.

Goodwin, C., K.L. Smith, and S. Spiggle. 1990. Gift giving: Consumer motivation and the gift purchase process. Adv. Consum. Res. 17:690-698.

Hair, J.F., Jr., W.C. Black, B.J. Babin, and R.E. Anderson. 2010. Multivariate data analysis: A global perspective. 7th ed. Prentice Hall, Upper Saddle River, NJ.

Haviland-Jones, J., H.H. Rosario, P. Wilson, and T.R. McGuire. 2005. An environment approach to positive emotion: Flowers. Evol. Psychol. 3:104-132.

Huang, L. 2005. Floral product behaviors and their influence on consumer floral purchase frequency. HortTechnology 15:766-771.

Joy, A. 2001. Gift giving in Hong Kong and the continuum of social ties. J. Consum. Res. 28(2): 239-256.

Kim, H.H., Y.J. Kyung, K. Ohkawa, C.H. Park, and B.H. Kwack. 1999. Flower industry in Korea. Acta Hort. 482:407-414.

Kleinbaum, D.G., L.L. Kupper, A. Nizam, and K.E. Muller. 2008. Applied regression analysis and other multivariable methods. 4th ed. Thomson, Belmont, CA.

Komter, A. and W. Vollebergh. 1997. Gift giving and the emotional significance of family and friends. J. Marriage Fam. 59(3):747-757.

Kras, J. 1999. Marketing of cut flowers in the future. Acta Hort. 482:401-406.

Kuo, C. 1997. The differences of conspicuous consumption, green consumer orientations, and gift giving behaviors among the people of Taiwan as a result of socioeconomic backgrounds and residential areas (in Chinese). J. Advert. Pub. Relat. 9:1-20.

Lai, Y. and L. Huang. 2013. The effect of relationship characteristics on buying fresh flowers as romantic Valentine's Day gifts. HortTechnology 23:28-37.

Laroche, M., G. Saad, M. Cleveland, and E. Browne. 2000. Gender differences in information search strategies for a Christmas gift. J. Consum. Mktg. 17(6):500-522.

Larsen, D. and J.J. Watson. 2001. A guide map to the terrain of gift value. Psycho. Mktg. 18(8):889-906.

Microsoft. 2003. Excel 2003. Microsoft corp., Redmond, WA.

Mortelmans, D. and D. Sinardet. 2004. Reflecting culture and society? Norms and rules governing gift-giving practice. Netherland's J. Soc. Sci. 40(2):176-201.

National Retail Federation. 2011. NRF 2011 Holiday consumer spending trends. National Retail Federation, Washington, D.C. 4 Feb. 2013. <http:// www.nrf.com/modules.php?name=News\&op= viewlive \&sp id $=1223>$.

National Statistics of Taiwan. 2011. Statistical database for cities and counties, Taipei, Taiwan. 24 Apr. 2014. <http://ebas1.ebas.gov.tw/ pxweb/Dialog/statfile9.asp>.

Neisser, M. 1973. The sense of self expressed through giving and receiving. Soc. Casework 54(5):294-301.

Otnes, C., T.M. Lowrey, and Y.C. Kim. 1993. Gift selection for easy and difficult recipients: A social roles interpretation. J. Consum. Res. 20(2): 229-244.

Otnes, C., J.A. Ruth, and C.C. Milbourne. 1994. The pleasure and pain of being close: Men's mixed feelings about participation in Valentine's Day gift exchange. Adv. Consum. Res. 21:159-164.
Rihn, A.L., C. Yue, B. Behe, and C. Hall. 2011. Generations $\mathrm{X}$ and $\mathrm{Y}$ attitudes toward fresh flowers as gifts: Implications for the floral industry. HortScience 46:736-743.

Roster, C.A. 2006. Moments of truth in gift exchanges: A critical incident analysis of communication indicators used to detect gift failure. Psychol. Mktg. 23(11):885-903.

Rugimbana, R., B. Donahay, C. Neal, and M.J. Polonsky. 2003. The role of social power relations in gift giving on Valentine's Day. J. Consum. Behav. 3(1):63-73.

Rupp, K. 2003. Gift giving in Japan: Cash, connections, cosmologies. Stanford Univ. Press, CA.

Ruth, J.A. 2004. Gift exchange rituals in the workplace: A social roles interpretation, p. 181-211. In C.C. Otnes and T.M. Lowrey (eds.). Contemporary consumption rituals: A research anthology. Lawrence Erlbaum Associates, Inc., Mahwah, NJ.

Saad, G. and T. Gill. 2003. An evolutionary psychology perspective on gift giving among young adults. Psychol. Mktg. 20(9):765-784.

Society of American Florists. 2005. Meet today's floral consumer. Society of American Florists, Chicago, IL. 6 Apr. 2014. <http://www.safnow. org/node $/ 201>$.

Society of American Florists (SAF). 2012a. SAF PR campaign tells consumers how to get hip to floral gift giving. Society of American Florists, Chicago, IL. 28 Aug. 2012. <http://safcms. memberfuse.com/node $/ 200>$.

Society of American Florists. 2012b. Consumer trends on buying flowers. Society of American Florists, Chicago, IL. 28 Aug. 2012. <http:// aboutflowers.com/about-the-flower-industry/ consumer-trends.html>.

Society of American Florists. 2012c. Research shows where flowers rank on gift lists. Society of American Florists, Chicago, IL. 28 Aug. 2012. <http://safcms.memberfuse.com/node/208>.

Scammon, D.L., R.T. Shaw, and G. Bamossy. 1982. Is a gift always a gift? An investigation of flower purchasing behavior across situations. Adv. Consum. Res. 9(1):531-536.

Schiffman, L.G. and D.Y. Cohn. 2009. Are they playing by the same rules? A consumer gifting classification of marital dyads. J. Bus. Res. 62:1054-1062.

Schwartz, B. 1967. The social psychology of the gift. Amer. J. Sociol. 73(1):1-11.

Sherry, J.F., Jr. 1983. Gift giving in anthropological perspective. J. Consum. Res. 10(2):157-169.

Sherry, J.F., Jr., M.A. McGrath, and S.J. Levy. 1993. The dark side of the gift. J. Bus. Res. 28 (3):225-244.

SPSS. 2007. SPSS 17.0. IMB Corp., Armonk, NY.

Wagner, J., R. Ettenson, and S. Verrier. 1990 The effect of donor-recipient involvement on consumer gift decisions. Adv. Consum. Res. 17(1):683-689.

Wagner, J. and T. Garner. 1993. Extrahousehold giving in popular gift categories: A socioeconomic and demographic analysis. Adv. Consum. Res. 20:515-519.

Wooten, D.B. 2000. Qualitative steps toward an expanded model of anxiety in gift giving. J. Consum. Res. 27(1):84-95.

Yeh, T. and L. Huang. 2009. An analysis of floral consumption values and their difference for genders and geographic regions. HortTechnology 19:101-107.

Yue, C., A. Rihn, B. Behe, and C. Hall. 2009. Consumer preference for flowers as gifts: Age segments, substitutes, and perceived risk. American Floral Endowment, Alexandria, VA.

Ziegler, C. 2007. Favored flowers: Culture and economy in a global system. Duke Univ. Press, Durham, NC. 